\title{
BMH-21 inhibits viability and induces apoptosis by p53-dependent nucleolar stress responses in SKOV3 ovarian cancer cells
}

\author{
XINXU FU ${ }^{1 *}, \mathrm{LU} \mathrm{XU}^{1 *}$, LING QI ${ }^{1}$, HONGYAN TIAN $^{2}, \mathrm{DAN} \mathrm{YI}^{3}, \mathrm{YANG} \mathrm{YU}^{1}$, \\ SHIBING LIU ${ }^{1}$, SONGYAN LI ${ }^{1}$, YE XU ${ }^{1,2}$ and CHUNYAN WANG ${ }^{1}$ \\ ${ }^{1}$ Tumor Targeted Therapy and Translational Medicine Laboratory, ${ }^{2}$ Department of Histology and Embryology, \\ Basic College of Medicine, Jilin Medical University; ${ }^{3}$ Physical Examination Center, \\ Jilin Integrated Traditional Chinese and Western Medicine Hospital, Jilin, Jilin 132013, P.R. China
}

Received November 5, 2016; Accepted May 22, 2017

DOI: 10.3892/or.2017.5750

\begin{abstract}
The nucleolus is a stress sensor associated with cell cycle progression and apoptosis. Studies have shown that nucleolar stress is positively correlated with apoptosis in breast, prostate and lung cancer cells. However, the role and function of nucleolar stress in ovarian cancer has not been reported. In this study, we found that the nucleolar stress inducer BMH-21 inhibited viability of SKOV3 ovarian cancer cells in a dose-dependent manner. Furthermore, BMH-21 induced the expression of nucleolar stress marker proteins (nucleolin, nucleophosmin and fibrillarin) and promoted the nuclear export of these proteins. BMH-21 also decreased MDM2 proto-oncogene expression and increased protein levels of the tumor suppressor p53 and p53 phosphorylated at serine 15 (p-p53-Ser15), which contributed to increased expression of the downstream apoptosis-related protein BCL2 associated X (BAX) and activation of caspase-3. Taken together, these data provide the first reported evidence that induction of $\mathrm{p} 53$-dependent nucleolar stress by BMH-21 induces apoptosis in ovarian cancer. Our data suggest that nucleolar stress might be a pathway suitable for targeting in ovarian cancer.
\end{abstract}

\section{Introduction}

Ovarian cancer, the seventh most common cancer among women, remains one of the leading causes of cancer-associated morbidity and mortality. It has become the third most common

Correspondence to: $\mathrm{Dr} \mathrm{Ye} \mathrm{Xu}$, Department of Histology and Embryology, Basic College of Medicine, Jilin Medical University, 5 Jilin Street, Jilin, Jilin 132013, P.R. China

E-mail: xuye_9707@sina.cn

Dr Chunyan Wang, Tumor Targeted Therapy and Translational Medicine Laboratory, Basic College of Medicine, Jilin Medical University, 5 Jilin Street, Jilin, Jilin 132013, P.R. China

E-mail: april_wang2000@hotmail.com

*Contributed equally

Key words: BMH-21, nucleolar stress, p53 signaling, apoptosis, ovarian cancer cancer of female genital organs, after cervical cancer and endometrial cancer $(1,2)$. cis-Dichlorodiammineplatinum (II) (cisplatin) has been the standard of care against ovarian cancer for several decades. However, its clinical efficacy is often limited by extrinsic and intrinsic drug resistance as well as nephrotoxicity (3). Hence, there is an urgent need to identify new molecular targets in ovarian cancer. Recent studies have shown that nucleolar stress plays a role in cancer cell viability and apoptosis.

The nucleolus is a cellular organelle within the nucleus where ribosomal DNA (rDNA) transcription and ribosome biogenesis occur $(4,5)$. It comprises distinct subcompartments, and is divided into the granular compartment (GC), the dense fibrillar component (DFC) and the fibrillar center (FC) (6). The structural stability of the three subcompartments is important in their role in nucleolar function. Nucleolar stress (also called ribosomal stress) is caused by failures in ribosome assembly and ribosome biogenesis. This then inhibits RNA polymerase I (Pol I) transcription that finally results in the dysfunction of cellular homeostasis. Internal and extrinsic stimuli, such as abnormal metabolic conditions, ultraviolet irradiation and enhanced levels of reactive oxygen species, can lead to nucleolar stress (7). Nucleolar stress inhibits viability and induces apoptosis of cancer cells in vivo and in vitro $(6,7)$. Hence, targeting nucleolar stress as a potential therapeutic strategy for cancer has already attracted attention.

BMH-21, a planar tetracyclic small molecule, preferentially binds GC-rich DNA sequences and inhibits RNA polymerase I (Pol I) transcription, finally leading to nucleolar stress and apoptosis. BMH-21 has a broad-spectrum anticancer effect by potently and rapidly repressing Pol I independently of DNA damage signaling. The aberrant Pol I transcription induces nucleolar reorganization and activates p53 thus contributing to apoptosis $(8,9)$. Peltonen et al have reported that BMH-21 has extensive and potent antitumor activity across NCI60 cancer cell lines and inhibits the growth of tumors in vivo (10). However, the mechanism of action of BMH-21 in ovarian cancer cell death remains poorly understood.

The aim of this study was to explore whether BMH-21 induces apoptosis in SKOV3 ovarian cancer cells and explore the mechanism. Herein, we report that BMH-21 inhibited viability and induced apoptosis in SKOV3 cells through a 
p53-dependent nucleolar stress response pathway. These data suggest that induction of nucleolar stress using an inducer such as BMH-21 may be a novel strategy for ovarian cancer therapy.

\section{Materials and methods}

Cell culture. SKOV3 human ovarian cancer cells, Bel-7402 human hepatic cancer cells and HeLa human cervical cancer cells were obtained from the Chinese Academy of Medical Sciences. The cells were cultured at $37^{\circ} \mathrm{C}$ in a $5 \% \mathrm{CO}_{2}$ atmosphere at Roswell Park Memorial Institute (RPMI)-1640 culture medium (Gibco, Carlsbad, CA, USA) supplemented with $10 \%$ fetal bovine serum (Invitrogen, Carlsbad, CA, USA), $100 \mathrm{U} / \mathrm{ml}$ penicillin, and $100 \mathrm{U} / \mathrm{ml}$ streptomycin. The experiment was divided into 4 groups: a control group, $1 \mu \mathrm{M}$ BMH-21 (SMl1183; Sigma, USA) group, $2 \mu$ M BMH-21 group and $4 \mu \mathrm{M}$ BMH-21 group.

MTT assay. Cell viability was determined by MTT assay. SKOV3, Bel-7402 and HeLa cells in the exponential growth phase were seeded into 96-well culture plates in $100 \mu \mathrm{l}$ RPMI-1640 at a density of $8 \times 10^{3}$ cells/well. After 24 -h incubation, the indicated dose of BMH-21 was added to the 24-h incubation in four parallel wells. MTT assays (Beyotime Institute of Biotechnology, Haimen, China) were performed as follows: $20 \mu 1$ MTT solution $(5 \mathrm{mg} / \mathrm{ml})$ in phosphate-buffered saline (PBS; Beijing Zhongshan Golden Bridge Biological Technology Co., Ltd., Beijing, China) was added to cells for $4 \mathrm{~h}$, after which $150 \mu \mathrm{l}$ dimethyl sulfoxide (Beijing Chemical Industry Co.,Ltd., Beijing, China) was added to each well.Cells were agitated for $10 \mathrm{~min}$ prior to absorbance measurements at $570 \mathrm{~nm}$ using a Microplate Reader (Bio-Rad Laboratories, Hercules, CA, USA). The growth inhibition rate was calculated as $\%$ inhibition $=1-$ absorbance of experimental group / absorbance of control group x 100 . The mean value of the four replicate wells was calculated for each treatment group.

Cell cycle analysis. Exponentially growing ovarian cancer cells were seeded into 6-well culture plates at a density of $2 \times 10^{5}$ cells/well. After exposure to different experimental conditions, the cells were trypsinized and resuspended in RPMI-1640 with $10 \%$ FBS at a concentration of $1 \times 10^{6}$ cells $/ \mathrm{ml}$. For cell cycle analysis, the cells were washed with phosphate-buffered saline (PBS) and fixed with 70\% ice-cold ethanol. Cells were then stained with propidium iodide (PI). Cell cycle graphs were acquired using the BD Accuri ${ }^{\mathrm{TM}}$ C6 flow cytometry system (BD Biosciences, USA) using BD Accuri C6 software. For each sample, $\geq 1 \times 10^{4}$ cells were recorded. ModFit Cell cycle analysis software was used to analyze the percentage of cells in G0/G1, S and G2/M phases based on DNA content.

Immunofluorescence staining and confocal laser microscopy. Cells were seeded onto coverslips in 24-well plates at a density of $5 \times 10^{4}$ cells/well for $24 \mathrm{~h}$ before treatment, and then treated with increasing doses of BMH-21 (1,2 and $4 \mu \mathrm{M})$ for $24 \mathrm{~h}$. After treatment, cells were washed three times with cold $0.1 \mathrm{M}$ PBS and fixed in 4\% (w/v) paraformaldehyde/PBS for 20-30 min, stained with the nuclear stain Hoechst $33342 / \mathrm{H}_{2} \mathrm{O}$ (2 $\mu \mathrm{g} / \mathrm{ml}$, Sigma) for $30 \mathrm{~min}$, washed with $0.01 \mathrm{M}$ PBS, and examined using Olympus FV1000 confocal laser microscopy to reveal chromatin condensation. The expression and localization of nucleolin (1:1,400 dilution, Abcam, Hong Kong, China), nucleophosmin (1:1,400 dilution, Abcam) and fibrillarin (1:1,400 dilution, Abcam) were examined. Cells were cultured on coverslips overnight, then treated with the indicated drugs, and rinsed with $0.1 \mathrm{M}$ PBS three times. After incubation, the cells were fixed with $4 \%$ paraformaldehyde for $20 \mathrm{~min}$, permeabilized with $0.1 \%$ Triton X-100 (Sigma-Aldrich) for $5 \mathrm{~min}$, washed three times with $0.01 \mathrm{M}$ PBS, blocked for $30 \mathrm{~min}$ in 5\% (w/v) non-immune animal serum (goat) (Beyotime Biotechnology, Shanghai, China) PBS, and incubated with primary antibody overnight at $4^{\circ} \mathrm{C}$. The next day, the slides were incubated with the Alexa Fluor-488/546-conjugated secondary antibody (1:400 dilution; Invitrogen) for $1 \mathrm{~h}$, then stained with Hoechst $33342(2 \mu \mathrm{g} / \mathrm{ml})$ for 2 min and washed three times with PBS. After mounting, the cells were examined by Olympus FV1000 confocal laser microscopy.

Western blot analysis. Protein concentrations were measured using a Bio-Rad Protein assay kit (Bio-Rad Laboratories). For western blot analysis, protein lysates $(30-50 \mu \mathrm{g})$ were separated on a $12 \%$ SDS-PAGE gel and $15 \%$ SDS-PAGE gel and transferred onto an Immobilon-P membrane (EMD Millipore, Billerica, MA, USA). The membranes were blocked with $5 \%$ non-fat dry milk in buffer $(10 \mathrm{mM}$ Tris- $\mathrm{HCl}, \mathrm{pH} 7.6$; $100 \mathrm{mM} \mathrm{NaCl}$; and $0.1 \%$ Tween-20) for $2 \mathrm{~h}$ at room temperature and then incubated with the appropriate primary antibodies overnight at $4^{\circ} \mathrm{C}$. Antibodies used were: anti-p53 and antip-p53-Ser15 (1:1,000 dilution, SAB, College Park, MD, USA), anti-MDM2 (1:1,000 dilution, SAB), anti-Bax (1:1,000 dilution, Proteintech Group ${ }^{\circledR}$, Chicago, IL, USA), anti-caspase-3 (1:1,000 dilution, Abcam) and anti- $\beta$-actin (1:1,000 dilution, Proteintech Group). The following day, membranes were incubated with horseradish peroxidase-conjugated secondary antibody (Thermo, Waltham, MA, USA) at a 1:2,000 dilution for $2 \mathrm{~h}$ at room temperature. Membranes were then incubated in ECL reagents and images were captured by Syngene Bio Imaging (Synoptics, Cambridge, UK). Densitometric quantitation of bands was performed using Syngene Bio Imaging tools. Data are presented as the mean \pm standard deviation (SD) from three independent experiments.

Statistical analysis. Results are expressed as means \pm standard deviation (SD) or means \pm standard error of mean (SEM), as indicated in the figure legends. Data are representative of three independent experiments performed in triplicate. Statistical analysis of the data was performed using one-way ANOVA. The Tukey's post hoc test was used to determine the significance for all pairwise comparisons of interest. Differences were considered statistically significant for values of $\mathrm{P}<0.05$.

\section{Results}

BMH-21 inhibits the viability of cancer cells. To evaluate the inhibitory effect of BMH-21 on SKOV3, Bel-7402 and HeLa cell viability, cells were treated with increasing doses of BMH-21 for $24 \mathrm{~h}$ and cell viability was determined by an MTT assay. BMH-21 treatment decreased the viability of SKOV3, Bel-7402 and HeLa cells in a dose-dependent manner (Fig. 1A, E and F). Based on MTT results, we treated 


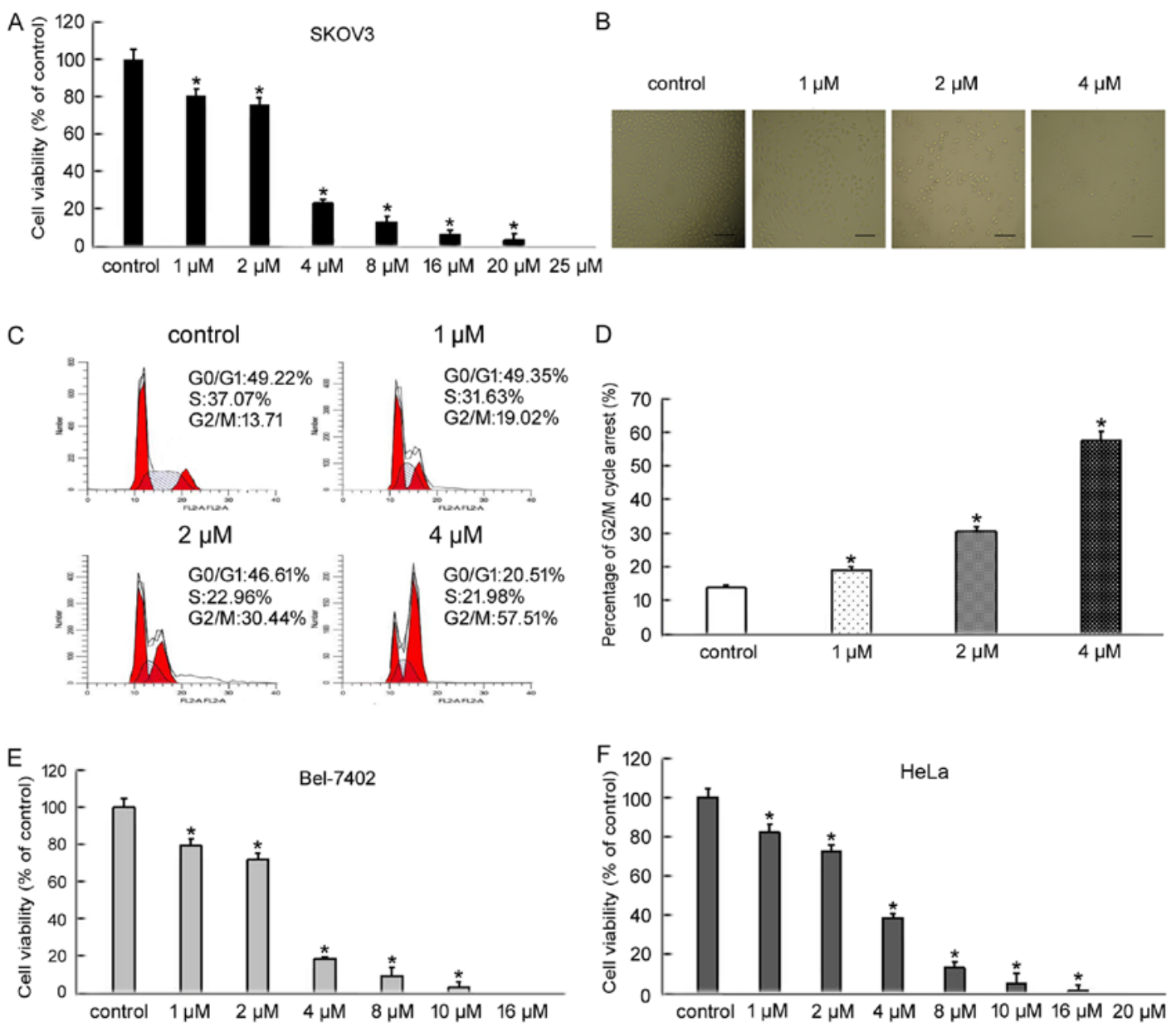

Figure 1. BMH-21 inhibits the viability of cancer cells. (A, E and F) SKOV3, Bel-7402 and HeLa cells were treated with varying doses of BMH-21 for $24 \mathrm{~h}$. Cell viability was determined by the MTT assay. (B) Images were captured using an inverted phase contrast microscope at a magnification of x100 (scale bar, $50 \mu \mathrm{m})$. (C and D) SKOV3 cells were treated with varying doses of BMH-21 $(1,2$ and $4 \mu \mathrm{M})$ for $24 \mathrm{~h}$. Cells were stained with propidium iodide, and the cell cycle distribution was analyzed by flow cytometry. Data are presented as mean $\pm \mathrm{SD}, \mathrm{n}=3$. ${ }^{*} \mathrm{P}<0.05$ vs. control.
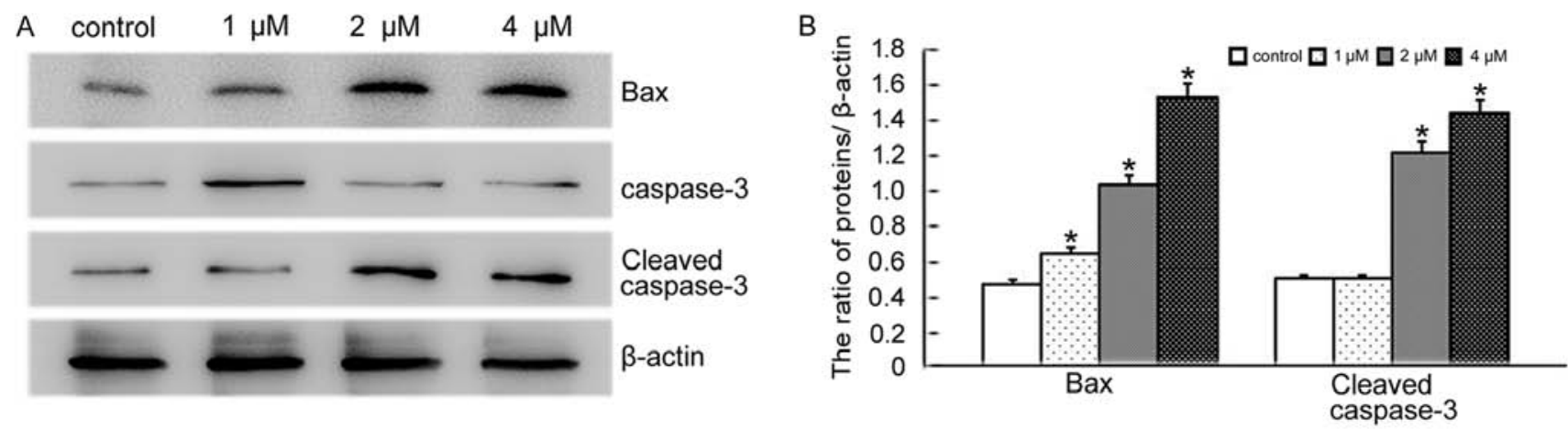

C
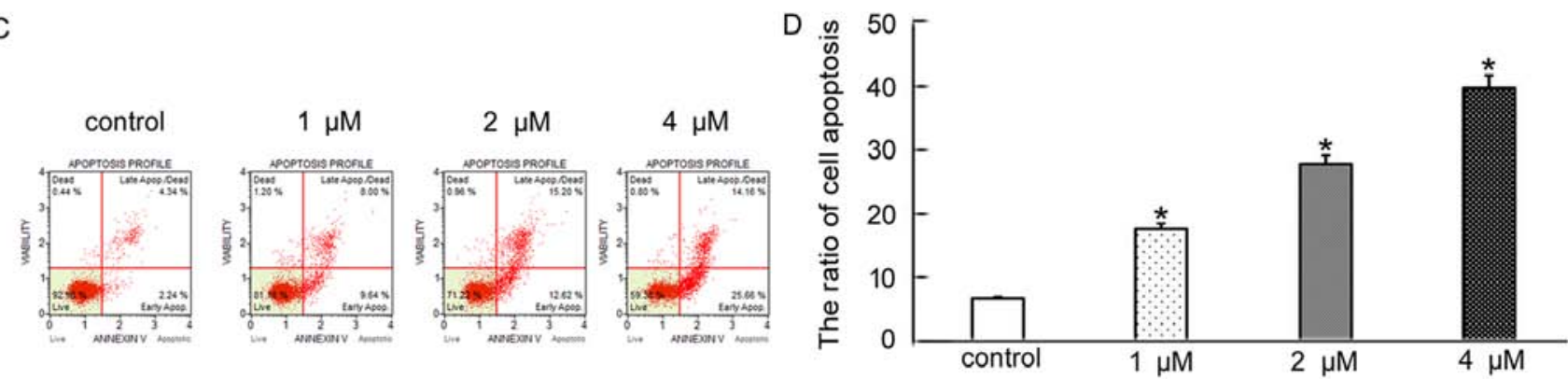

Figure 2. BMH-21 induces apoptosis in SKOV3 cells. (A) SKOV3 cells were treated with varying doses of BMH-21 (1,2 and $4 \mu \mathrm{M})$ for $24 \mathrm{~h}$. Expression of BAX and cleaved caspase-3 were determined by western blotting. (B) Quantitation of BAX and cleaved caspase-3 protein levels. (C and D) Apoptosis was assessed by staining for Annexin V and 7-AAD, and analysed by Muse cell analyser. Data are presented as mean $\pm \mathrm{SD}, \mathrm{n}=3$. ${ }^{*} \mathrm{P}<0.05$ vs. control. 

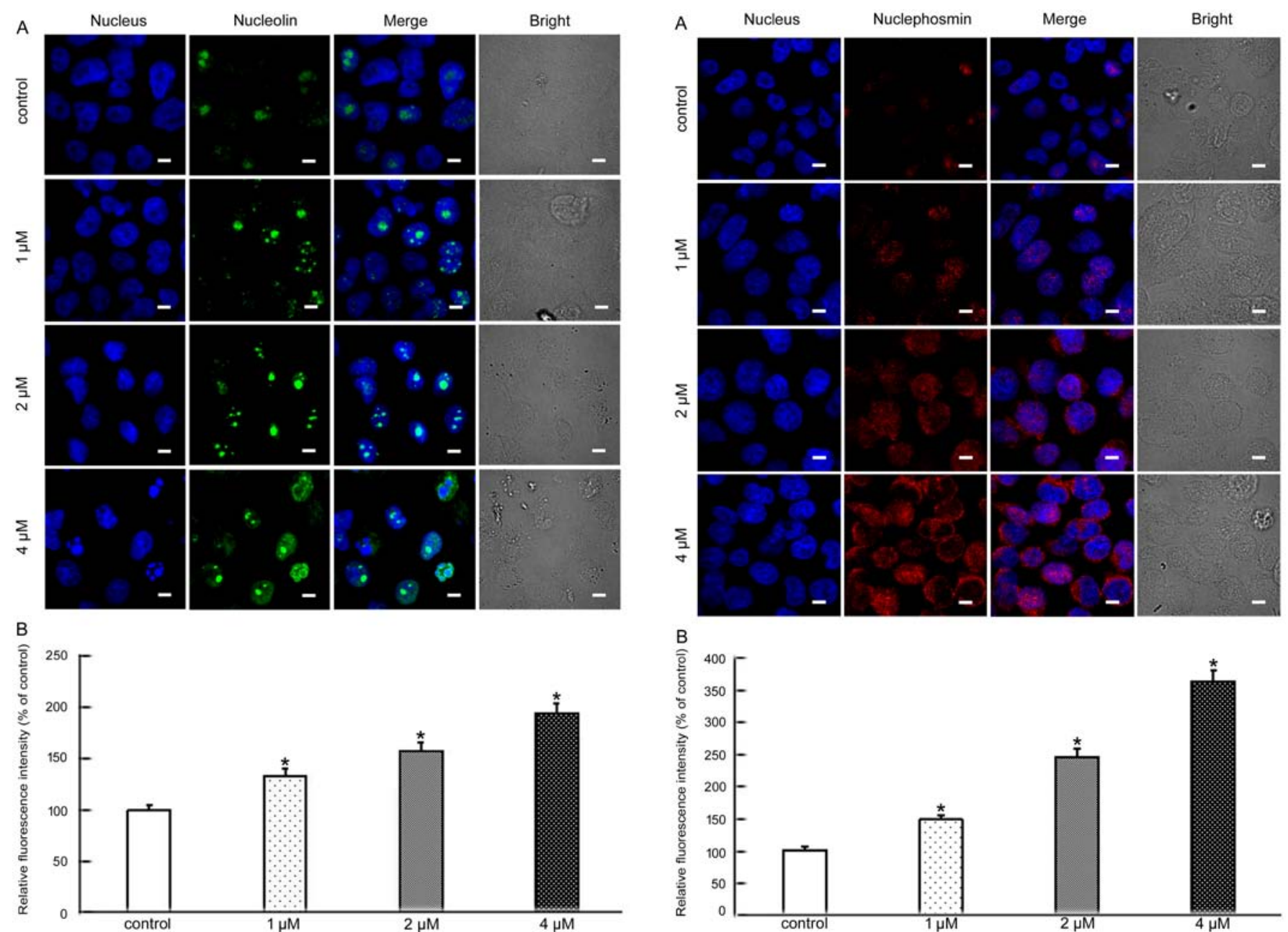

Figure 3. BMH-21 induces nucleolin expression and its cytoplasmic compartmentalization in SKOV3 cells. (A) SKOV3 cells were treated with varying doses of BMH-21 (1,2 and $4 \mu \mathrm{M})$ for $24 \mathrm{~h}$. The expression and cellular localization of nucleolin was observed using confocal microscopy (scale bar, $5 \mu \mathrm{m}$ ). (B) Quantitation of expression of nucleolin. Data are presented as mean $\pm \mathrm{SD}$, $\mathrm{n}=3$. ${ }^{*} \mathrm{P}<0.05$ vs. control.

SKOV3 cells with increasing doses of BMH-21 (1,2 and $4 \mu \mathrm{M})$ for $24 \mathrm{~h}$. We examined the changes in SKOV3 cell morphology using an inverted optical microscope. The cells treated with BMH-21 became fragmented and round when compared with control cells (Fig. 1B). To examine the distribution of cell cycle progression, we confirmed the effect of BMH-21 in various cell cycle phases using flow cytometry. BMH-21 resulted in a marked increase in the percentage of cells blocked at $\mathrm{G} 2 / \mathrm{M}$ phase (Fig. 1C and D). These findings indicated that BMH-21 effectively inhibited cancer cell viability and suggested that BMH-21 induced cell death.

BMH-21 induces apoptosis in SKOV3 cells. BCL2 associated $\mathrm{X}$ (BAX), a member of the BCL2 family, is a pro-apoptotic protein. Overexpression of BAX triggers the release of mitochondrial proteins that cleave and thereby activate caspase-3 resulting in apoptosis (11). We therefore decided to explore if the morphological changes seen after BMH-21 treatment were a result of apoptotic induction in SKOV3 cells. Based on the MTT results, SKOV3 cells were treated with the same doses of

Figure 4. BMH-21 induces nucleophosmin expression and its cytoplasmic compartmentalization in SKOV3 cells. (A) SKOV3 cells were treated with varying doses of BMH-21 (1,2 and $4 \mu \mathrm{M})$ for $24 \mathrm{~h}$. The expression and cellular localization of nucleophosmin was observed using confocal microscopy (scale bar, $5 \mu \mathrm{m}$ ). (B) Quantitation of expression of nucleophosmin. Data are presented as mean $\pm \mathrm{SD}, \mathrm{n}=3$. ${ }^{*} \mathrm{P}<0.05$ vs. control.

BMH-21 for $24 \mathrm{~h}$ and the levels of BAX and cleaved caspase- 3 were detected by western blotting. The results showed that the levels of BAX and cleaved caspase-3 increased in BMH-21 treated cells, compared with the control group (Fig. 2A and B). Additionally, flow cytometry analysis revealed that BMH-21 induced SKOV3 cell apoptosis in concentration-dependent manner (Fig. 2C and D). The results suggested that BMH-21 induces apoptosis in SKOV3 cells through a BAX-caspase-3 pathway.

BMH-21 induces nucleolar stress in SKOV3 cells. Nucleolin, nucleophosmin and fibrillarin, the major nucleolar proteins of proliferating eukaryotic cells, play an important role in nucleolar stress. When nucleolar stress occurs, the levels of these three proteins increase and the proteins translocate from the nucleus to the cytoplasm $(12,13)$. Nucleolin is the major nucleolar protein of exponentially growing eukaryotic cells, and participates in many modulations including rDNA transcription, RNA metabolism, and ribosome assembly (14). Nucleophosmin is a highly and ubiquitously expressed 


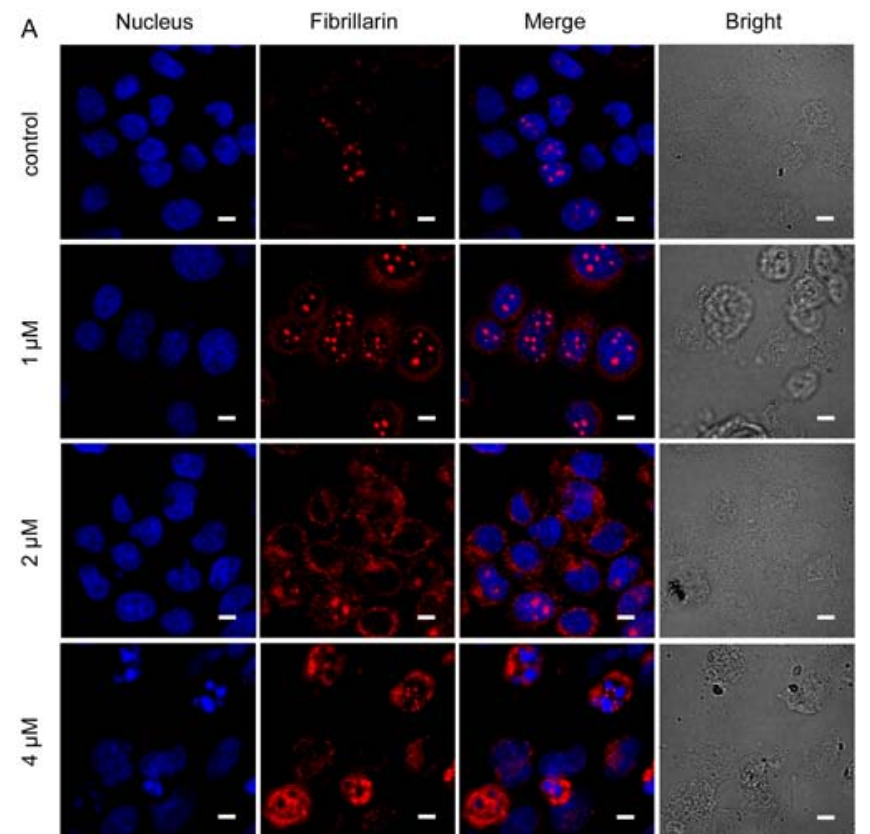

B

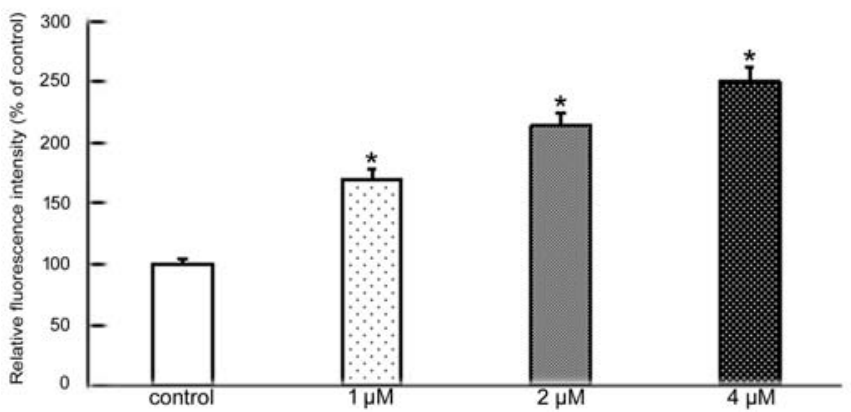

Figure 5. BMH-21 induces fibrillarin expression and its cytoplasmic compartmentalization in SKOV3 cells. (A) SKOV3 cells were treated with varying doses of BMH-21 (1, 2 and $4 \mu \mathrm{M})$ for $24 \mathrm{~h}$. The expression and cellular localization of fibrillarin was observed using confocal microscopy (scale bar, $5 \mu \mathrm{m}$ ). (B) Quantitation of expression of fibrillarin. Data are presented as mean $\pm \mathrm{SD}, \mathrm{n}=3 .{ }^{*} \mathrm{P}<0.05$ vs. control.

protein, and plays crucial roles in ribosome maturation and export, centrosome duplication and cell cycle progression (15). Fibrillarin is one of the most studied nucleolar proteins and also is an early marker for the site of formation of the newly forming nucleolus. Its main functions are methylation and processing of pre-rRNA (16). To further analyze the molecular mechanisms of apoptosis induced by BMH-21 we explored whether nucleolar stress was involved. The level and cellular localization of nucleolin, nucleophosmin and fibrillarin were examined by confocal microscopy. These results showed that $\mathrm{BMH}-21$ increased the levels of all three proteins and resulted in their nuclear exclusion (Figs. 3-5). This suggested that BMH-21 induced nucleolar stress in SKOV3 cells.

BMH-21 activates p53 signaling pathway in SKOV3 cells. There is increasing evidence that suggests nucleolar stress can lead to induction of the p53 pathway in cells. Under normal conditions, MDM2 proto-oncogene (MDM2) binds directly to p53, promoting the degradation of p53 and inhibiting its activity (17). Nucleolar stress causes disruption of MDM2-p53 binding, leading to decreased MDM2 levels and increased p53
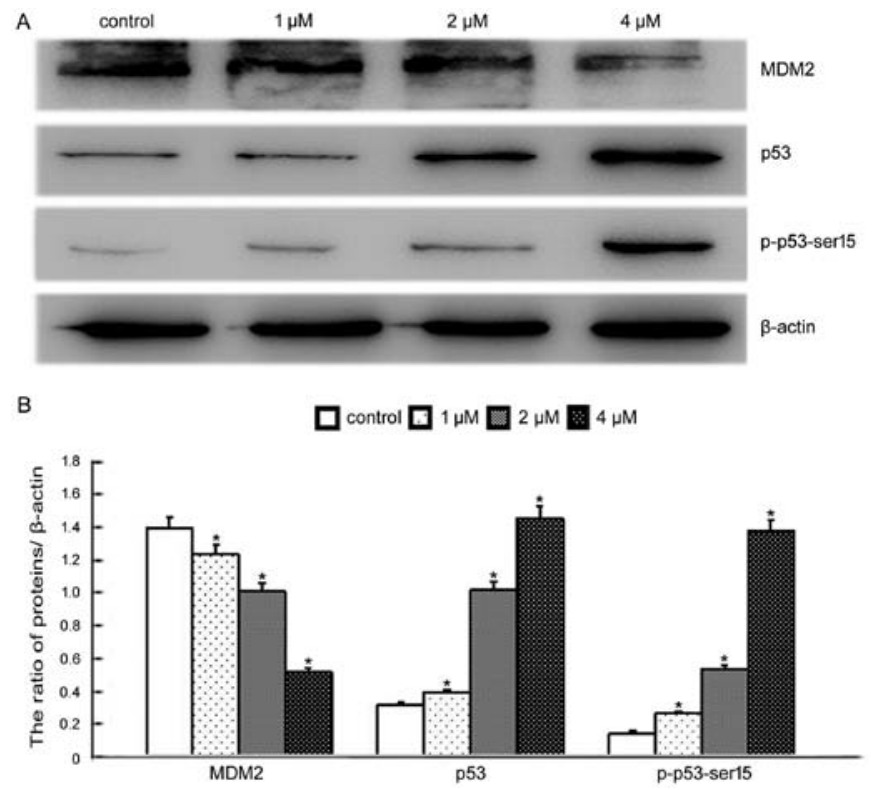

Figure 6. BMH-21 activates p53 signaling pathway in SKOV3 cells. (A) SKOV3 cells were treated with varying doses of BMH-21 (1, 2 and $4 \mu \mathrm{M})$ for $24 \mathrm{~h}$. Expression of MDM2, p53 and p-p53-Ser15 were determined by western blotting. (B) Quantitation of MDM2, p53 and p-p53-Ser15 protein levels. Data are presented as mean $\pm \mathrm{SD}, \mathrm{n}=3$. ${ }^{*} \mathrm{P}<0.05$ vs. control

and p-p53-Ser15 levels (18). We therefore investigated whether BMH-21-induced nucleolar stress had an impact on the p53 pathway. Western blotting was conducted to determine the levels of MDM2, p53 and p-p53-Ser15. These results indicated that BMH-21 treatment decreased MDM2 levels, increased p53 and p-p53-Ser15 levels in a dose-dependent manner (Fig. 6), supporting the involvement of the p53 pathway in the response to BMH-21 in SKOV3 cells.

\section{Discussion}

Ovarian cancer remains the most common gynecologic tumor of the genital tract. Cisplatin is the most commonly used and effective chemotherapeutic drug for ovarian cancer. Patients with ovarian cancer usually respond well to initial chemotherapy with cisplatin. However, most patients develop resistance to cisplatin during the course of their treatment $(1,19)$. Hence, there is an urgent need to identify new therapeutic targets in ovarian cancer and to develop novel, potent and specific drugs. Negi et al reported that BMH-21 selectively killed cancer cells by nucleolar stress while sparing normal cells, suggesting that the nucleolus is a potential new target area in tumor treatment (20). In our study, we found that BMH-21 inhibited viability and induced apoptosis in a dosedependent manner (Figs. 1 and 2).

The nucleolus is a specialized sub-nuclear compartment of eukaryotic cells where rRNA synthesis and ribosome assembly take place. Recent studies have shown that, apart from its traditional function, the nucleolus plays a vital role in viral replication, control of aging, cell cycle regulation, and apoptosis (21-24). The perturbation of ribosome synthesis, induced by various stimuli, can lead to nucleolar stress (23). In recent years, research has focused on the relationship 
between nucleolar stress and cancer (25). As proliferating tumor cells have enhanced ribosome biogenesis compared with normal somatic cells, the tumor cells are more sensitive to nucleolar stress and this provides a therapeutic window (26). Interestingly, Quin et al proposed that inhibition of nucleolar stress represented an emerging hallmark of cancer and thus the nucleolus would be a potential target for cancer treatment (6). Nucleophosmin, nucleolin and fibrillarin are ubiquitously expressed nucleolar multifunctional proteins, and can act as markers for nucleolar stress (27). Nucleolar stress not only induces expression of these proteins, but also contributes to their translocation from the nucleus to the cytoplasm, thus activating downstream death signaling processes. In the present study, we found that BMH-21 induced the translocation of nucleophosmin, nucleolin and fibrillarin to the cytoplasm (Figs. 3-5), suggesting that nucleolar stress had occurred.

The tumor suppressor protein p53 is a downstream effector of nucleolar stress. Under normal circumstances, the E3 ubiquitin ligase MDM2 binds to p53 and is involved in the degradation of $\mathrm{p} 53$ by the ubiquitin-proteasome system leading to very low levels of p53 (28-31). After nucleolar stress, a number of ribosomal proteins bind to MDM2 disrupting its interaction with p53. MDM2 expression is then decreased thus leading to p53 stabilization and activation (32). Activation of p53 is reported to be controlled by phosphorylation of p53 at critical serine residues in the $\mathrm{N}$ terminus. When activated, p-p53-Ser15 induces cell cycle arrest or apoptosis via induction of a series of target genes (including $B A X, P M A I P I$ and $B B C 3)(33,34)$. Further evidence has been provided by Lin $e$ al who showed that tubeimoside-1 (TBMS1) induced nucleolar stress and apoptosis in the human lung cancer cell line NCI-H460. The nucleolar stress was dependent on a p53/MDM2 mechanism, suggesting that p53-dependent nucleolar stress may be responsible for the death effect of TBMS1 (35). Consistent with the above reports, we found that BMH-21 decreased MDM2 expression, increased p53 and p-p53-Ser15 expression (Fig. 6).

In conclusion, the present study demonstrated that BMH-21 induced nucleolar stress responses, and resulted in the accumulation of the tumor suppressor protein p53 and p-p53-Ser15, thus inhibiting the viability and inducing apoptosis in SKOV3 cells. Our data provide new insights into the mechanism of nucleolar stress and suggest that nucleolar stress is a potential target for ovarian cancer therapy.

\section{Acknowledgements}

This study was supported by the National Nature and Science Foundation of China (81372793 and 81671041). The Department of Education of Jilin Province Project (no. 2016237), and Scientific Research Foundation of Jilin Province for University Students. The authors would like to thank Director Dominic James from Liwen Bianji (Edanz Group China) for the language editing of this manuscript.

\section{References}

1. Xie S, Zheng H, Wen X, Sun J, Wang Y, Gao X, Guo L and Lu R: MUS81 is associated with cell proliferation and cisplatin sensitivity in serous ovarian cancer. Biochem Biophys Res Commun 476: 493-500, 2016.
2. Gershenson DM and Frazier AL: Conundrums in the management of malignant ovarian germ cell tumors: Toward lessening acute morbidity and late effects of treatment. Gynecol Oncol 143: 428-432, 2016.

3. Wijdeven RH, Pang B, Assaraf YG and Neefjes J: Old drugs, novel ways out: Drug resistance toward cytotoxic chemotherapeutics. Drug Resist Updat 28: 65-81, 2016.

4. Yang L and Chen J: SirT1 and rRNA in the nucleolus: Regulating the regulator. Oncoscience 1: 111-112, 2014.

5. Hariharan N and Sussman MA: Stressing on the nucleolus in cardiovascular disease. Biochim Biophys Acta 1842: 798-801, 2014.

6. Quin JE, Devlin JR, Cameron D, Hannan KM, Pearson RB and Hannan RD: Targeting the nucleolus for cancer intervention. Biochim Biophys Acta 1842: 802-816, 2014.

7. Hein N, Hannan KM, George AJ, Sanij E and Hannan RD: The nucleolus: An emerging target for cancer therapy. Trends Mol Med 19: 643-654, 2013.

8. Colis L, Ernst G, Sanders S, Liu H, Sirajuddin P, Peltonen K, DePasquale M, Barrow JC and Laiho M: Design, synthesis, and structure-activity relationships of pyridoquinazolinecarboxamides as RNA polymerase I inhibitors. J Med Chem 57: 4950-4961, 2014.

9. Peltonen K, Colis L, Liu H, Jäämaa S, Moore HM, Enbäck J, Laakkonen P, Vaahtokari A, Jones RJ, af Hällström TM, et al: Identification of novel p53 pathway activating small-molecule compounds reveals unexpected similarities with known therapeutic agents. PLoS One 5: e12996, 2010.

10. Peltonen K, Colis L, Liu H, Trivedi R, Moubarek MS, Moore HM, Bai B, Rudek MA, Bieberich CJ and Laiho M: A targeting modality for destruction of RNA polymerase I that possesses anticancer activity. Cancer Cell 25: 77-90, 2014.

11. Zhang X and $\mathrm{Yu} \mathrm{H}$ : Matrine inhibits diethylnitrosamine-induced HCC proliferation in rats through inducing apoptosis via p53, Bax-dependent caspase-3 activation pathway and downregulating MLCK overexpression. Iran J Pharm Res 15: 491-499, 2016.

12. Colis L, Peltonen K, Sirajuddin P, Liu H, Sanders S, Ernst G, Barrow JC and Laiho M: DNA intercalator BMH-21 inhibits RNA polymerase I independent of DNA damage response. Oncotarget 5: 4361-4369, 2014.

13. Stepiński D: Immunodetection of nucleolar proteins and ultrastructure of nucleoli of soybean root meristematic cells treated with chilling stress and after recovery. Protoplasma 235: 77-89, 2009.

14. Chen $\mathrm{Z}$ and $\mathrm{Xu} \mathrm{X}$ : Roles of nucleolin. Focus on cancer and anticancer therapy. Saudi Med J 37: 1312-1318, 2016.

15. Chopra A, Soni S, Pati H, Kumar D, Diwedi R, Verma D, Vishwakama G, Bakhshi S, Kumar S, Gogia A, et al: Nucleophosmin mutation analysis in acute myeloid leukaemia: Immunohistochemistry as a surrogate for molecular techniques. Indian J Med Res 143: 763-768, 2016.

16. Shubina MY, Musinova YR and Sheval EV: Nucleolar methyltransferase fibrillarin: Evolution of structure and functions. Biochemistry (Mosc) 81: 941-950, 2016.

17. Holmberg Olausson K, Nistér $M$ and Lindström MS: p53 -dependent and -independent nucleolar stress responses. Cells 1: 774-798, 2012.

18. Trino S, Iacobucci I, Erriquez D, Laurenzana I, De Luca L, Ferrari A, GhelliLuserna Di Rorà A,Papayannidis C, Derenzini E, Simonetti G, et al: Targeting the p53-MDM2 interaction by the small-molecule MDM2 antagonist Nutlin-3a: A new challenged target therapy in adult Philadelphia positive acute lymphoblastic leukemia patients. Oncotarget 7: 12951-12961, 2016.

19. Sun Y, Jin L, Liu JH, Sui YX, Han LL and Shen XL: Interfering EZH2 expression reverses the cisplatin resistance in human ovarian cancer by inhibiting autophagy. Cancer Biother Radiopharm 31: 246-252, 2016.

20. Negi SS and Brown P: rRNA synthesis inhibitor, CX-5461, activates ATM/ATR pathway in acute lymphoblastic leukemia, arrests cells in G2 phase and induces apoptosis. Oncotarget 6: 18094-18104, 2015.

21. Nicolas E, Parisot P, Pinto-Monteiro C, de Walque R, De Vleeschouwer C and Lafontaine DL: Involvement of human ribosomal proteins in nucleolar structure and p53-dependent nucleolar stress. Nat Commun 7: 11390, 2016.

22. Eliopoulos AG and Volarevic S: TPL2-NPM-p53 pathway monitors nucleolar stress. Oncoscience 2: 892-893, 2015.

23. Boulon S, Westman BJ, Hutten S, Boisvert FM and Lamond AI: The nucleolus under stress. Mol Cell 40: 216-227, 2010. 
24. Sloan KE, Bohnsack MT and Watkins NJ: The 5S RNP couples p53 homeostasis to ribosome biogenesis and nucleolar stress. Cell Rep 5: 237-247, 2013.

25. Huang M, Whang P, Lewicki P and Mitchell BS: Cyclopentenyl cytosine induces senescence in breast cancer cells through the nucleolar stress response and activation of p53. Mol Pharmacol 80: 40-48, 2011.

26. Russo A, Pagliara V, Albano F, Esposito D, Sagar V, Loreni F, Irace C, Santamaria R and Russo G: Regulatory role of $\mathrm{rpL} 3$ in cell response to nucleolar stress induced by Act D in tumor cells lacking functional p53. Cell Cycle 15: 41-51, 2016.

27. Qin R, Jiang W and Liu D: Aluminum can induce alterations in the cellular localization and expression of three major nucleolar proteins in root tip cells of Allium cepa var. agrogarum L. Chemosphere 90: 827-834, 2013.

28. Parkosadze G, Burkadze G, Mizandari M, Sulakvelidze M and Sanikidze T: Role of proapoptotic p-53 factor in pathogenesis of nonalcoholic hepatosteatosis. Georgian Med News 2: 55-60, 2013 (In Russian).

29. James A, Wang Y, Raje H, Rosby R and DiMario P: Nucleolar stress with and without p53. Nucleus 5: 402-426, 2014.

30. Xu J, Han M, Shen J, Guan Q, Bai Z, Lang B, Zhang H, Li Z, Zuo D, Zhang W, et al: 2-Methoxy-5((3,4,5-trimethosyphenyl) seleninyl) phenol inhibits MDM2 and induces apoptosis in breast cancer cells through a p53-independent pathway. Cancer Lett 383: 9-17, 2016.
31. Sriraman A, Li Y and Dobbelstein M: Fortifying p53 - beyond Mdm2 inhibitors. Aging (Albany, NY) 8: 1836-1837, 2016.

32. Barone G, Tweddle DA, Shohet JM, Chesler L, Moreno L, Pearson AD and Van Maerken T: MDM2-p53 interaction in paediatric solid tumours: Preclinical rationale, biomarkers and resistance. Curr Drug Targets 15: 114-123, 2014.

33. Liang $\mathrm{L}$ and Zhang Z: Gambogic acid inhibits malignant melanoma cell proliferation through mitochondrial p66shc/ ROS-p53/Bax-mediated apoptosis. Cell Physiol Biochem 38: 1618-1630, 2016.

34. Alshatwi AA, Subash-Babu P and Antonisamy P: Violacein induces apoptosis in human breast cancer cells through up regulation of BAX, p53 and down regulation of MDM2. Exp Toxicol Pathol 68: 89-97, 2016.

35. Lin Y, Xie G, Xia J, Su D, Liu J, Jiang F and Xu Y: TBMS1 exerts its cytotoxicity in NCI-H460 lung cancer cells through nucleolar stress-induced p53/MDM2-dependent mechanism, a quantitative proteomics study. Biochim Biophys Acta 1864: 204-210, 2016. 